\title{
Psychological Aspects of Economic Behavior of People
}

\author{
Sergey A. Surkov \\ International Institute of Management, Moscow, Russia \\ *Corresponding Author: context2002@yandex.ru
}

Copyright (C 2014 Horizon Research Publishing All rights reserved.

\begin{abstract}
Psychological foundations of human activities have changed. This applies to Economy. If before the foundation of human behavior was the fact that is hidden and open sexuality, but now her value is reduced. Aggressiveness comes to the fore. The notion of aggressiveness is coming to the forefront. Its components can be approximately express in the indicators by G.Hofstede. Poverty can be linked to the rate of economic development through indicators of aggressiveness. The use of psychological approaches will clarify many of the economic models.
\end{abstract}

Keywords Aggression, Economic Returns, Clarify of the Model, Poverty, Economic Growth

\section{Introduction}

Management of the human community, in spite of numerous attempts ideological, is based on economic approaches. However, the features of economic behavior cannot be considered separately from human nature. The vast majority of economic theories are based on ideas about the validity of the model of "economic man". That is, on the notion that human behavior is fully determined by its economic condition. This is partially true, but it reduces human till the role of a kind of vending machine, to which you can invest money and get the product, for example, a pack of cigarettes. In the case of the model of "economic man" in the role of a "pack of cigarettes" performs behavior of the individual.

Nevertheless, the human psyche is much more difficult, especially since the behavior of people in the society is as a minimum an order of magnitude more complex. That is why the existing theories so bad predict basic events of economic development like defaults, crises, periods of stagnation and recovery, the uneven development of the countries and the emergence of the debtor countries, etc. In connection with this fact, scientists are constantly making efforts in area the integration of economics and psychology, as evidenced, for example, the subjects of the works that have received the last three Nobel Prize in economics.

\section{Literature Review}

But and this approach does not cover all the features of the analysis of economic behavior of people. There appear "new discoveries", which narrow down all of the complexity of the economy to the physiological aspects of the life of the organism. In particular, according to J. Coates [1] such hormones as testosterone, so influence the behavior of bankers that financial booms and bankruptcy almost inevitable. The level of testosterone increases aggression and self-confidence, but also leads to an exaggeration of its own values, which leads to unjustified risks. Furthermore, the opinions expressed and the fact that the economy is not an exact science. [2]. Anyone, who thinks that this is an area of knowledge have deal only with the mathematical relations, is mistaken

The object of the study of economics is people. However, their economic behavior, much cannot be a numeric measurement, because the economic processes affect psychology, which, in the opinion of B.A.Payzbepga [2], cannot be measured by numbers. The fact is that not enough use of the provisions of social psychology. But in fact, she considers the relationships between people in society, including those that make up the content of economic activity, so that the study of human psychology is not enough. In addition, individual psychology is based on a number of assumptions that are already partially obsolete, or do not belong to the mainstream of economic development.

These ideas include the theory of sexuality influence on the current community life. Until now taken to explain all the features of the human person, and therefore the complexity of social life, directly or indirectly arising out of sexual aspirations of individuals. All his thoughts and acts are interpreted as a projection that of implemented or, conversely, crushed, sexuality. These views based on looks of Freud and his followers. However, already at the same time, when these theories have been put forward, and there arise criticism [3]. However, this criticism concerned the particulars of theoretical positions, without affecting their essence as a whole.

Attempts were made to link the role of psychological processes and economic phenomena. It is, generally speaking, it is quite logical, since the economy cannot be divorced from psychology, as evidenced by the recognition of the validity of this approach, as noted above, for the last three years the Nobel Prize in Economics. Sexual relations 
with the exception of exotic practices are interactions between two people, and, accordingly, the deepest layers of the psyche. These original layers, are essential for the animal, is typical reactions of organism. Not only in humans, but even in higher primates, sexual relations are modified with social experience. The rapid changes in the actual practice of formalization of sexual relations in the past decade have the form of marriage in the form of a civil, trial form, the guest form, a serial form, etc., indicate dissatisfaction the people of these forms.

This can be presented as a difference between the actual role of sex and the attention that is given to them in the public mind. The logical extension of this position is the idea that the importance of sexuality in the life of society has fallen. This is indicated by reduction in the level and quality of sexual relations, for example, in [4], where there was a decrease in the frequency of sex in Western Europe, up to people like A.Vasserman, which completely far from sexual activity [5].

Accordingly, the use of sexual motivation, for example, in advertising, does not the former recoil. O. Bedareva [6] writes that sometimes the practice gives examples of inefficiency sexual advertising where it should work. Now it is clear that the well-known statement that "sex sells" is devoid of reason. Thus, we can conclude about reducing the role of sex in society

Earlier this side of life was something of a secret, forbidden, especially in the Middle Ages, when there were persecutions of those who are trying to study or to depict the human body. Gradually, the situation has changed, and since the beginning of XX century was implemented cult healthy body, which has found its quintessence in nudism and naturism

Occurred sexual revolution and has made the further emancipation of the people in the sexual area. Distribution of nudist beaches, opportunity to openly discuss the issue of sexual activity in literature, represent sex on the Internet, has led to the fact that this area is no longer taboo, and is losing its role in shaping the psyche of people on the basis of the "forbidden fruit sweetness." This, incidentally, is one of the real sources of the above-noted lack of effectiveness of advertising campaigns based on sexual motives.

However, the human community cannot allow the emergence of "emptiness" in the psyche of its members, and partly "free space" of repressed sexuality in need of replacement and / or supplement something else. This is a different are aggressiveness of the human individual. The man - a large aggressive predator, and over millions of years of social development of its essence has not changed

14.5 thousand big and small wars were happened in the known history of humanity [7]. War was not only 300 years. [8]. Direct destruction of their own kind, other than purely humanitarian aspects, economically disadvantageous. In the end, the leaders of Nazi Germany were convinced of it. If not timely break down she the ridge by the Red Army with help of Allied. Today Germany has achieved by economic hegemony on the continent by purely economic measures by doing something for what she untied the last two world wars.

The loss ratio has led to the fact that mankind has learned to sublimate this aggression. Many activities of human are the sublimation of aggression, in particular, entrepreneurial activity. Apparently, this is one of the reasons for the success of those entrepreneurs from Russia, who are not connected with the administrative resources. In 2011, Russia ranked $153 \mathrm{rd}$ out of 158 in the ranking index of peacefulness of the Institute for Economics and Peace [9], which is calculated on the basis of external indicators. Russia is a place where citizens treat each other with increased aggressiveness. This manifests itself in daily life.

L. Petranovskaya [10] writes that when released into the Russia, the mind and body of the Russians instantly evaluates the environment as unsafe and toggles the body into combat status.

Further L. Petranovskaya [10] notes that the man is, by nature, is a weak animals. Therefore, he had very little the instinctive programs upon replacement of tussles by rituals. Consequently, people should "themselves reinvent" something to the replace of direct aggression, from the rituals of courtesy until the championships on football, from subtle irony until the proceedings, from frontiers and diplomacy until the mass demonstrations and trade unions. People are aggressive, but have learned to live with it.

\section{Methods}

The main method used in this paper is to compare various quantities characterizing the different aspects of human life. This applies in particular to the sublimation of aggression.

Sublimation and its consequences in social psychology is measurable, which is extremely important for the economy in the aspect of the study of the influence of psychological mechanisms of economic behavior. In economics, there are a number of concepts that determine the suitable level of economic development. Economic development is perfectly measurable in concrete units, although they are have quite relative nature. As an example, the real value of money is often significantly different from the official rate. However, indicators of economic development are clear and well understood.

Many of the characteristics from the field of social psychology, where she is in contact with the economy, can only be regarded as illusory, existing in the minds of people. As an example, can be consider an indicator such as the conflict. Such who are busy in the practical management, knows that this index could greatly influence the micro-economic indicators of the company, but he could hardly amenable to measurement. It is not clear what and how to monitor it and what units to measure. In units of "oblique views", "harsh words", "cold attitude", etc., it is impossible to measure, it is too uncertain quantities, and spend time and money on these "dimensions" no one will.. To interview experts, and thus obtain a "snapshot", "replica" or "make an impression" to understand the level of conflict 
is possible. But these perceptions exist only in the minds of experts, and therefore illusory. .Similar surveys can identify other important for economy the social-psychological or economic indicators. For example, the author and his colleagues [11] compared the average salary in 26 different cities of Russia in the polls and the official data. Very good matching obtained with the official data, which proves the applicability of the method for the quantitative study of the survey indicators. Every man is a social person, and even recluses, denying the human society, thereby suggesting him presence and expressing his attitude. Therefore, aggression occurs only in society or in relation to the environment. However, as the author has shown the results of the survey 226 respondents and content analysis in four search engines on the Internet Yandex, AltaVista, Google, Yahoo, on average, people show their aggression in society at $92.32 \%$, and in the environment - $6 \%$, mostly in the form of direct damage from vandalism and other damages of nature. The sample of respondents in the study cover an array of managers, which is receiving training in the MBA program.

The other share of the aggressiveness is unknown and they continue to retain the character of the unallocated portion. This is easily explained if we recall the days when a man take possession of unfounded and no one else directed anger and rage. These feelings "erupting" on the first available live or inanimate object and, apparently, for the most part, this is consistent with the aforementioned undistributed share of total aggression.

It should be noted that the description of the human psyche into the interpersonal interaction is possible to do by different methods and with different indicators. Sometimes such a review reminds popular at one time conversion formula thermodynamic and thermal quantities, consideration of which was soon abandoned because of their lack of prospects. As an example we give graph shown in Figure 1, which contains quite clear about the fact that with increase in the level of human development index HDI, poverty is reducing. Although in the far side of the diagram clearly visible the area of the plateau, an array of points can be interpreted as a linear relationship.

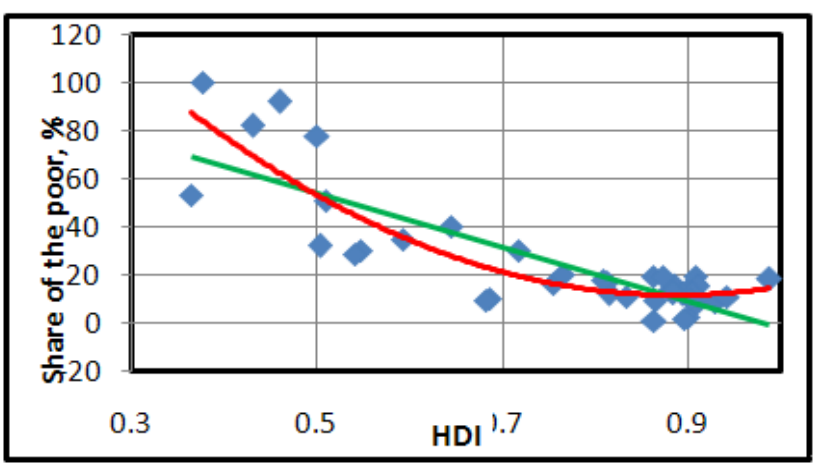

Figure 1. Comparison of the human development index with a share of the poor in different countries

Despite the pronounced dependence graph Figure 1 does not add to the knowledge about the real processes in the economy, because without it, it is clear that in countries with a high HDI, namely, in the developed countries, the share of the poor will be less than that of developing countries, countries with low HDI.

We have to find a real psychological basis of economic processes. One such base may be to evaluate the sublimation of aggression through entrepreneurial activities. Accordingly, there exists a realization of aggression in society since of other capabilities, to a first approximation, we can neglect. You can specify that a large part of the manifestations of aggression have the shape of the background, general social concern, and is manifested in the impact of the mass of people on the individuum. We evaluate the relationship between economic performance and poverty, and we will consider in more detail the reasons for the latter.

O.S.Dejneka [12] points out that economists and sociologists, cultural and psychologists offer different concept of poverty based on the opposite methodological and ideological positions. According to her, in particular in economic psychology (psychology economic entity) in the representations of concepts of poverty are three groups of causes of poverty - structural, individualistic and fatalistic. The neoclassical answer to the question about the causes of poverty is as follows. [13]. Distribution of income in a market economy is based on the first place, to the right of ownership of the factors of production.

From the market prices of the factors of production is determined by the value of each of these types of income. The extremely low wages of workers is compared to the performance of work, and it is the specificity of Russia, which is a derivative of the Soviet economy. Low wages leads to reduced domestic demand, blocks the development of the internal market, reduces the motivation of labor, reduces the incentives of growth of labor productivity and economic growth.

\section{Theory}

We define the individual components of the psychological impact on the economic performance and we can determine the influence of various social and psychological factors on their magnitude. One of the strongest negative stimuli for the person in the society is the level infernality as a social concept. It can be explained as follows. If a man stood up in the morning to work, trying to shave, but is ended shaving cream and razor blades, is broken coffee maker, a favorite tie untied, on the way to work was bitten by a stray dog, a man splattered from car mud, left the tram that almost caught, in the next tram is affray and stole a purse, the only entrance to the building is not painted on Friday night, but on Monday morning, the chief "got off on the wrong foot," and he gave an undeserved "scolding", etc., his the actual productivity is clearly below the maximum possible. This is the level of the $\mathrm{Q}$ infernality in society through the harmful effects on humans. 
The second component of the negative impact of society on the individual member of society is $\mathrm{J}_{\mathrm{s}}$, the social pressure, and if infernality, despite specific manifestations, by definition, is impersonal, social pressure may have some personalization. Social pressure, in fact, is a combined, cumulative effects of economic, social, cultural and other standards on the life and work of the individual, which involve him in some social aggregation, the somehow, upon groups, social classes, strata, etc., forcing him to make a choice between accepting group, or, more generally, the of valuables of aggregation, or select the position of social outcast, an outsider. Personification consists in that the carrier of norms and values, most often, are the specific person or group of people, usually from the environment surrounding this any individual. Social pressure on ordinary citizens with examples of famous people are widely known phenomenon, forcing them to imitate. However, the most obvious illustration in this case can be seen as typical desire to buy the same car, a yacht, a villa, "as a neighbor Joe".

The third component of the negative impact on the people in the society is the level of personal aggressiveness of the individual man $A_{d}$. As a predator, he is focused on the capture and use of the maximum amount of resources and the protection of their own "hunting grounds". This ancient instincts that have contributed to the survival of the species, they are embedded in the subconscious of every person in the form of stable neural connections. No reason to break these ties and in the end there is no possibility to ensure that this will happen soon. This aggressiveness, as noted above, can be sublimated, but never disappears completely.

The fourth component is close in meaning to the third, but, in fact, different from the previous one, which is not implemented in the mind, but in real human activity. This component of vandalism $\mathrm{V}_{\mathrm{n}}$, which manifests itself as a desire for the destruction of inanimate objects, and cruelty to animals and of own kind. We can say that this component is similar to the accumulation of entropy and create chaos in place of the ordered structure. Vandalism different from the general aggressiveness in the fact that, unlike the latter, it does not sublimating, and are generally carried out in the event of disagreement between the inner and real milieu.

The fifth component represents the internal level of resistance, in essence, of the measure of antisocial level of individuals $\mathrm{H}_{\mathrm{s}}$. In this anti-social position there is a positive elements, in particular, resistance to various kinds of manipulations, such as NLP, "The Magic of sales representatives" and other impact on the human psyche, which describes R.Chaldini [14]. However, from an economic point of view, this component negatively affects the implementation of economic projects.

The sixth indicator, which gives a contribution to the negative developments in the economy, is the manifestation of negative emotions, such as anger, rage, envy, malice, etc., $F_{n}$. This indicator, by the way, is highly dependent on the national character. [15].

These negative components of the social impact is the aggression are opposed by positive trends, the core of which is the freedom of the will of S. Free will is an inherent and inalienable right and an opportunity for the individual to act in accordance with their attitudes, views and beliefs without degrading the environment and society on the whole. Complete the "sterility" in this sense in the relationship between man and the environment is not possible to achieve, and we must be guided by the principle of "reasonable sufficiency. The author's studies and the results of the survey 257 respondents show that the presence or absence of free will is a very strong motivator or, respectively, is a very strong demotivator. Mass support for Russian citizens' revolution white ribbons "is an expression of the possibility of manifestation of free will, even if not all and not always agrees with the goals and ideology of the protest movement. It is this aspect of action of people underestimated the authority because of his distrust of the people and the desire to limit the freedom of the will of ordinary people is not something that goes back to the days of the formation of the Russian Empire, but in those days, when appear the first principality. Therefore, the authorities and do not understand the importance and implications of these manifestations of free will, that can't stop the " on command" and limit the draconian law on fines for rallies. As shown by previous studies, the level of freedom gradually, albeit slowly, growing, and administrative methods can't do anything.

In addition to the freedom of the will, the activity of manifestation of the economic aspirations In addition to freedom of will, the totality of motivational mechanisms $\mathrm{M}$, which apply to the individuum, or rather the result of the impact of these mechanisms, contributes to the active manifestation of economic aspirations of the people.

Another indicator is determined by genetic inheritance, features educational influences and the influence of society, but in different proportions. The main thing here is the hereditary factor, as it is about the potential of the individual P. If the prerequisites for their implementation is not, then many ways economic realization of the human person are closed

The following components are a result of sublimation aggressiveness individuum. The first of these factors and the third in the sublimation has a creative component of human personality, which can be regarded as a projection on the plane of human creativity, innovation, new solutions, etc., $T_{v}$.

Such activity has a very large dynamic range. You can draw a parallel with the inventive work that extends from the improvement of push pin till teraflops computer project. It can be associated with theory by Atkinson-McClelland.

Another important positive factor in determining the positive results of human activities, is to own a positive signal to active economic action, internal "rod", $\mathrm{D}_{\mathrm{w}}$. It is the result of education, innate personal characteristics and the impact of public relations. People vary greatly in their innate activity actions. The level of such activity in the community has a significant impact on the development of society, and an important factor too is the percentage of those who "is entrepreneur" and the principle can't live otherwise, divided 
to the share of those who expected such actions from other.

The third positive component of sublimation and fifth in the row aggressiveness is the sports component of the personality of the individual $\mathrm{N}_{\mathrm{s}}$. Sport is a very effective sublimator as and entrepreneurship.

The sixth component is related to social development and the creation of social norms in a dorm with values and morals $\mathrm{C}_{\mathrm{m}}$.

Seventh component aggression in particular its sublimation is search knowledge of the environment $\mathrm{K}_{\mathrm{c}}$.

It should be noted that some of the above-mentioned indicators are self-contradictory, but, to a first approximation, these contradictions can be neglected. Elimination of contradictions is a task for future research.

You can create a function that is the sum of "positive" social-psychological factors. Thus to a first approximation, hereinafter assumed the presence phenomena of addictiveness socio-psychological factors. Such a function might look like this

$$
\mathrm{G}=\mathrm{M}+\mathrm{P}+\mathrm{D}_{\mathrm{w}}+\mathrm{T}_{\mathrm{v}}+\mathrm{N}_{\mathrm{s}}+\mathrm{C}_{\mathrm{m}}+\mathrm{S}+\mathrm{K}_{\mathrm{c}},
$$

Where

$\mathrm{M}$ - set of motivational mechanisms,

P-potential of the individual,

$D_{w}$ - activity-based component of the personality of the individual,

$\mathrm{T}_{\mathrm{V}}$ - creative component of the personality of the individual,

$\mathrm{N}_{\mathrm{s}}$ - the sports component of the personality of the individual,

$\mathrm{C}_{\mathrm{m}}$ - component associated with the values and morals,

$\mathrm{S}$-degree of freedom of will,

$\mathrm{K}_{\mathrm{c}}$-indicator of the desire for knowledge.

The second function is the sum of "negative" social-psychological factors

$$
\mathrm{U}=\mathrm{Q}+\mathrm{V}_{\mathrm{n}}+\mathrm{H}_{\mathrm{s}}+\mathrm{A}_{\mathrm{d}}+\mathrm{J}_{\mathrm{s}}+\mathrm{F}_{\mathrm{n}}
$$

wherein Q-as previously infernality level in society

$\mathrm{J}_{\mathrm{s}}$ - the level of social pressure,

$\mathrm{V}_{\mathrm{n}}$ - level "own" vandalism of the individual,

$\mathrm{H}_{\mathrm{s}}$ - the level of internal resistance to external influences,

$A_{d}$ - the level of aggressiveness of the individual,

$F_{n}$ - the level of manifestation of negative emotions.

The man in the course of daily activity is manifested in different ways, so you need to choose a universal approach to determine the indicators of psychodynamic. One of these approaches is the use of the model parameters of culture, developed G.Hofstede [16]. G.Hofstede use of performance indicators to determine the psychodynamic parameter is conditional and is used as a first approximation. Of course, need have possibility go to the direct determination of these parameters, for example, through surveys that will be carried out in future studies.

In his model, it is assumed that the national culture of the countries can be defined with indicators that describes by the five dimensions. Namely - "individualism-collectivism" IDV, "power distance" PDI, "uncertainty avoidance" UAI, "masculinity-femininity" MAS, "long-term orientations"
LTO. The latest available data is based on an analysis of 116 000 respondents completed questionnaires from 70 countries, and presented in [17]. Additional data for some countries of the world are reflected in the work [18]. In another study G.Hofstede [19] suggested interdependence between his the indicators and motivation and other characteristics that influence the behavior of people. Among other things, it defines motivation as a factor that is influenced by such factors as "collectivism-individualism" IDV, "uncertainty avoidance" UAI and "masculinity-femininity" MAS.

Using the approach G.Hofstede and applying the same reasoning for the other social -psychological factors in formula (1) and (2), can obtain expressions for these factors by the indexes patterns G.Hofstede. The level of motivation $\mathrm{M}=(\mathrm{IDV}+\mathrm{UAI}+\mathrm{MAS}) / 300$. The activity component can be represented as $D_{w}=I D V / 100$. The creative component is $\mathrm{T}_{\mathrm{v}}=(2 \mathrm{UAI}+\mathrm{MAS}) / 300$. Component associated with the values and morals defined by the expression $\mathrm{C}_{\mathrm{m}}=(2 \mathrm{IDV}+$ LTO) / 300. Sports component of the human person $\mathrm{N}_{\mathrm{s}}=$ $(\mathrm{IDV}+\mathrm{PDI}+\mathrm{LTO}) / 300$. Indicator of the potential in this case is assume to be the same for all countries, which corresponds to the humanistic traditions of the social sciences are required to take as a first approximation, the principle of equal opportunities for different people. The level freedom of will $\mathrm{S}$ can be defined as the degree of freedom of the individual PF from source [20]. Index on the level of commitment to the knowledge of $\mathrm{K}_{\mathrm{c}}$ determined based on the index knowledge KI [21]. The level of pure aggressiveness looks like $A_{d}=(M A S++$ IDV LTO) $/ 300$. The level of vandalism is $\mathrm{V}_{\mathrm{n}}=(2 \mathrm{IDV}+\mathrm{PDI}) / 300$. The level of internal resilience of individuums looks like a $\mathrm{H}_{\mathrm{s}}=(\mathrm{IDV}+$ MAS) / 200. Level infernality in society Q can be estimated on the basis of the International Index of happiness HPI [22] by the formula (100 - HPI) / 100. $\mathrm{J}_{\mathrm{s}}$ - the level of social pressure is determined using the index of life satisfaction SLI [23]. $\mathrm{J}_{\mathrm{s}}=(1000-\mathrm{SLI}) / 1000 . \mathrm{F}_{\mathrm{n}}$ - the level of manifestation of negative emotions is defined using the Global Index peacefulness GPI [24], of the $F_{n}=($ IDV + PDI $) / 300+1 /$ GPI These formulas are based on the fact that research of G.Hofstede done using 100-point scale, and in this study, all values are limited to a range from 0 to 1 . This kind of formula adopted in social psychology and based on the provisions of science of management, where, for example, similarly doing defining the motivational potential of the MPS [25]. For the more complete justification of the theory will require further research that will be done later.

\section{Results}

The assumption on additivity of G.Hofstede indicators have been used, as and the assumption of equality of treatment of indicators and assumption of equal levels of influence. As the results of other surveys and experiments of the author at least to a first approximation, these relations are satisfied. If compare the difference between the sums of "positive" and of "negative" factors, what is the driving force 
of social processes K.Levin [25], with a GNP per capita, can be obtain the dependence which shown on the Figure 2.

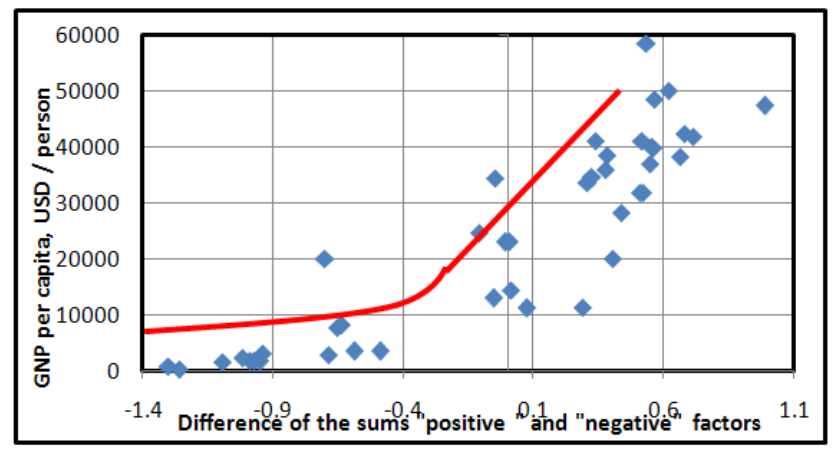

Figure 2. The relationship of GNP per capita and social forces

The graph in Figure 2 shows that the dependence has an inflection point near zero. That is, countries with low level of socio-psychological factor have low values of return (GDP) per capita.

This corresponds to the known data M. Malinoski [27]. The poverty rate would like to compare with the sum of positive factors. The higher the amount of "positive" factors, the higher motives which force people to act, and the level of poverty is lower. These provisions are confirmed by the graph in Figure 3.

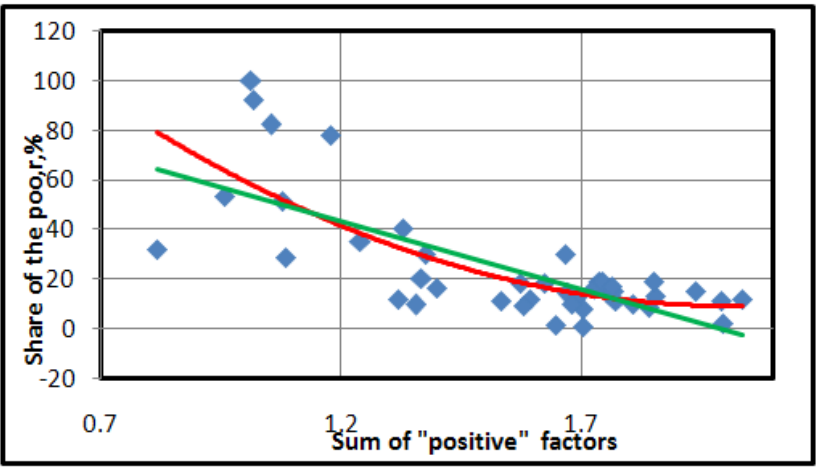

Figure 3. The dependence of the percentage of poor from the sum of "positive" factors

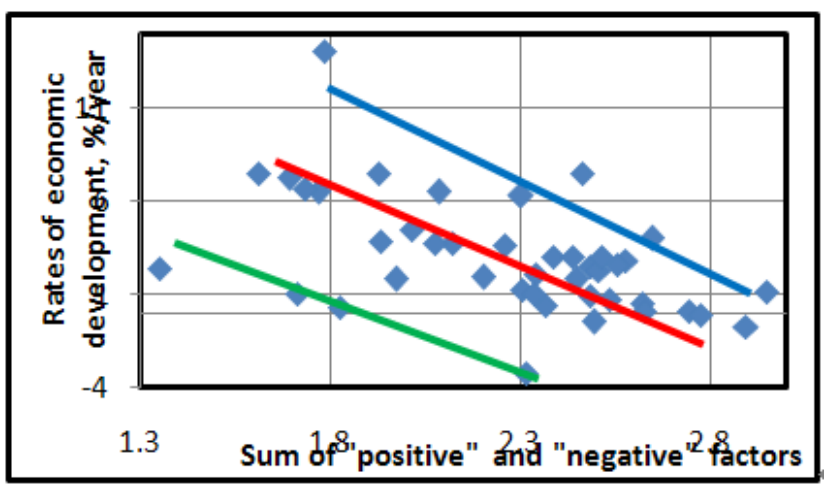

Figure 4. The relationship between the amount of "positive" and "negative" factors, with an economic growth rate

The correlation coefficient of -0.727 , and is significant for all significance levels that exceed the level of 0.01 . The regression equation is of the form $y=-54,73 x+108,9$. Similar arguments can also be applied to the pace of economic development, but in this case the relationship is more complicated. As seen from the graphs in Figure 4, an array of points can divide into three groups.

Using namely the amount of "positive" and "negative" factors relates to the fact that development depends on all the components associated with aggressiveness. Indicators of the regression lines are shown in Table 1.

Table 1. Indicators of the regression lines for the graphs in Figure 4

\begin{tabular}{|c|c|c|c|c|}
\hline Index & $\begin{array}{c}\text { The } \\
\text { correlation } \\
\text { coefficient }\end{array}$ & $\begin{array}{c}\text { The slope } \\
\text { coefficient } \\
\text { of points }\end{array}$ & $\begin{array}{c}\text { Absolute } \\
\text { term of } \\
\text { equation }\end{array}$ & Countries \\
\hline Upper & $-0,985$ & $-6,007$ & 10,91 & $\begin{array}{c}\text { Ghana, } \\
\text { Hong } \\
\text { Kong, } \\
\text { China, } \\
\text { Australia }\end{array}$ \\
\hline Middle & $-0,853$ & $-6,256$ & 17,15 & $\begin{array}{c}\text { The } \\
\text { remaining }\end{array}$ \\
\hline Nether & $-0,975$ & $-10,90$ & 33,10 & $\begin{array}{c}\text { Zakistan, } \\
\text { Sweden, } \\
\text { Portugal }\end{array}$ \\
\hline In total & $-0,517$ & $-4,308$ & 12,74 & - \\
\hline
\end{tabular}

The highest correlation coefficient gives displacement is by upper group - 6,5 vertically, and in the bottom group upon 7. This result is shown in Figure 5.

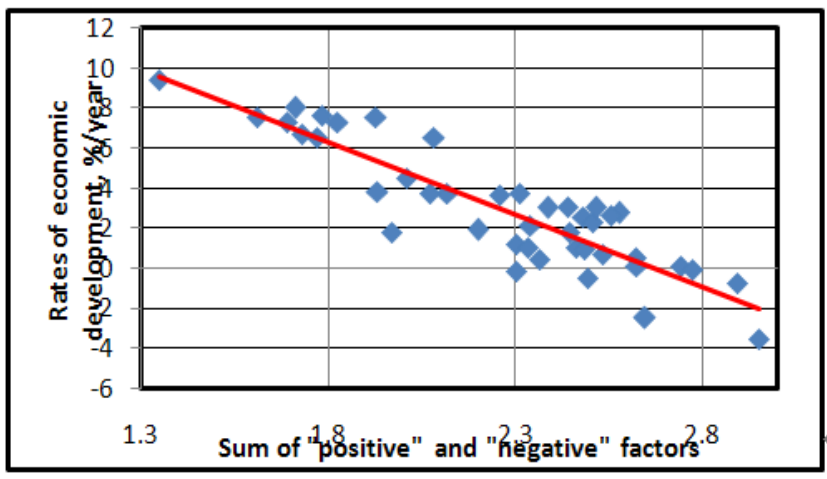

Figure 5. The revised schedule ratio of the sum of "positive" and "negative" factors, with economic growth

The correlation coefficient is of -0.893 for graph on Figure 5 has substantial for all significance levels that is greater than 0.01 . The regression equation, which was the goal of the transformations data set, has the form $y=-7,281 \mathrm{x}+19,41$.

\section{Verification of the theory (Discussion)}

A comparison of the regression equations reveals the relationship between economic growth and poverty as 


$$
\begin{gathered}
B=-54,73 G+108,9 \\
V=-7,281(G+U)+19,41
\end{gathered}
$$

Then we find that

$$
\mathrm{V}=\mathrm{B}[(\mathrm{G}+\mathrm{U})-2,67] /[7,52 \mathrm{G}-15]
$$

Calculations by the expression (3), and a comparison of the calculated values with the actual data for different countries, after removal using statistical criteria the "blunders", gives the graph shown in Fig. 6. "Gross blunders" most likely related to adopted above the conditional procedure recalculation economic growth rates taking into account the shift.

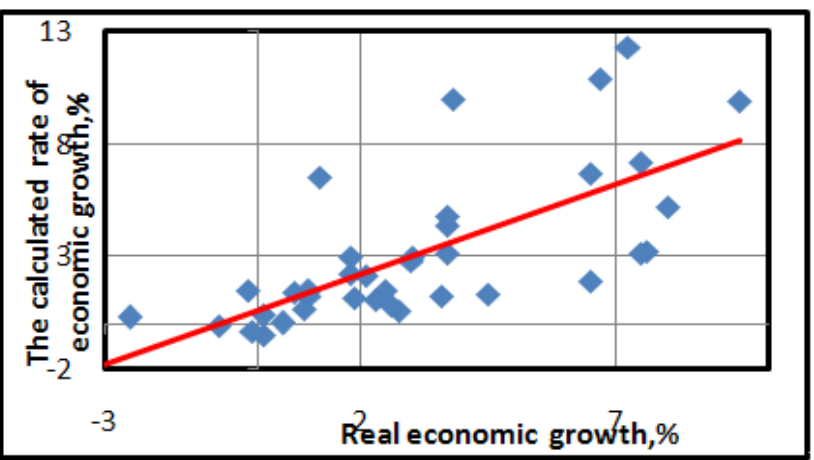

Figure 6. Comparison between calculated and measured pace of economic development

\section{Conclusion}

The correlation coefficient for the interrelationship in Figure 6, is equal to 0717 and is an essential for all levels of values greater than the level of 0.01 . The regression equation for the graph in Figure 6 is of the form $y=0,797 x+0,614$, which shows the deviation from the bisector of the quadrant and some understatement of the calculated values with the growth of this index. We also have a systematic overestimation of the magnitude indicator evenly on the free term of the equation. The author have had determined the applicability of the theory on the macroeconomic level, but assumes that it will be applicable in the case of smaller economic units.

Thus, the use of "psychological" factors can significantly change the economic model, and in the future will improve the quality of forecasting.

\section{Acknowledgements}

I express my gratitude Elena Trofimova for assistance in obtaining and processing information and Nadine Kalinina for help in translating this article.

\section{REFERENCES}

[1] M. Buchanan Hormone hangovers spell financial doom. New Scientist. 14.07.2012. Online available fromhttp://www.new scientist.com/blogs/culturelab/2012/06/hormone-hangovers-s pell-financial-doom.html

[2] B.A. Raizberg. Economics of words, numbers, reasoning and opinions. Elitarium. Centre for Distance Education. 03.08.12. Online available from http://www.elitarium.ru/2012/08/03/je konomika_slov_chisel_rassuzhdenij_mnenijj.html

[3] J.A.C Brown. Freud and the Post-Freudians. London: Penguin, 1961.

[4] I. A Gundarov. The new strategy of increasing fertility. History and modernity. Issue № 1,2009.

[5] O. Kozlova, A.Wasserman, "I regret that when has been the young man, taken a vow of celibacy." website "Mine!". Encyclopedia of Voronezh life. 14:07, 27.04.2010 № 806 of 27.04.2010.

[6] A. Bedareva When advertising is not exciting? Portal E-xecutive.ru. 26.06.2012. Online availablefromhttp://www. e-xecutive.ru/marketing/advertising/1678926

[7] P.K. Shatrov. Golden grain of wisdom. Volume 2, M.: The Bible for All, 2009

[8] A,I.Pershits, Y.I.Semenov, V.A. Shnirelman. War and Peace in the early history of humanity. TT 1-2. M., 1995

[9] Y.Kalachikhina. Russia recognized as one of the most aggressive countries. RBC daily, the daily business newspaper. 13.06.2012. Online available from http://www.rbcdaily.ru/2012/06/13/world/562949984093771

[10] L. Petranovskaya. Why are we so angry? Not dull garden. Journal of Orthodox life. Online available fromhttp://www.nsad.ru/articles/pochemu-my-takie-zlye

[11] S.A. Surkov, O.V. Skorikov, A.V. Gusev. Definition of economic indicators, using the methods of interviews. Marketing and marketing research, № 4, 2005, p.7-12.

[12] O.S. Dejneka. Constant poverty.Bee.Review of nongovernmental organizations in St. Petersburg \#37 (January-March 2002). Online available from http://www.pchela.ru/podshiv/37/boolen.htm

[13] I.B. Polyubina. Poverty as a phenomenon: causes, coping strategies. - E. Media "Viperson". March 11, 2011. Online available from http://www.viperson.ru

[14] R. B.Cialdini. Influence: Science and practice. Boston: Allyn \& Bacon,2001.

[15] Political psychology textbook for high schools. Ed. A.A . Derkach, V.I. Zhukov, L.G. Laptev. Moscow: Academic Project, Yekaterinburg: Business Book, 2001. - 858 pp.

[16] G. Hofstede. Culture's Consequences: International Differences in Work-Related Values. Beverly Hills, London:Sage,1980. Online available from http://www.geerthofstede.com/

[17] A. Naumov. The influence of national culture on business management. Online available from http://www.tpprf.ru/img /uploaded/2003110315353525.doc

[18] G. Hofstede. Dimensions of national cultures in fifty countries and three regions. In: J.B.Deregowski, S.Dzurawiec, R.C.Annis (eds). Explications in Cross-Cultural Psychology, 
Lisse, Nederlands: Swets and Zeitlinger, 1983, pp. 335-355.

[19] Website Happy Planet Index. Online available from http://www.happyplanetindex.org/data/

[20] I. Vásquez and T. Štumberger. An Index of Freedom in the Word. Online available from http://www.fraserinstitute.org/uploadedFiles/fraser-ca/Conte $\mathrm{nt} /$ research-news/research/publications/ch3-an-index-of-free dom-in-the-world.pdf

[21] KEI and KI Indexes 2009. The World Bank Group, July 2009. Online available fromhttp://gtmarket.ru/ratings/knowledge-economy-index/kn owledge-economy-index-info

[22] A. G. White, University of Leicester. A Global Project of Subjective Well-being, 2006. The Satisfaction with Life Index. Centre for Humanitarian Technologies. Humanities Technology and Human Development. Expert-analytical portal. Online available from http://gtmarket.ru/ratings/satisf action-with-life-index

[23] The Global Peace Index 2012.Economist Intelligence Unit,
Institute for Economics and Peace, 2012. Centre for Humanitarian Technologies. Humanities Technology and Human Development. Expert-analytical portal. Online available from http://gtmarket.ru/ratings/satisfaction-with-life-index

[24] Knowledge Economy Index and its indicators in countries of world. KEI and KI Indexes of 2009. The World Bank Group. Online available fromhttp://gtmarket.ru/ratings/knowledge-e conomy-index/knowledge-economy-index-info

[25] J.R.Hackman, G.Oldham, R.Janson, K.Purdy. A New Strategy for job Enrichment. California Management Review, 1975, Vol.17, №4.

[26] K. Lewin. Resolving social conflicts \& Field theory in social science. Washington, D.C.: American Psychological Association, 2008.

[27] M. Malinoski. On Culture and Income Inequality: Regression Analysis of Hofstede's International Cultural Dimensions and the Gini Coefficient. Xavier Journal of Politics, Vol.III, No.1, 2012. 